\title{
Preface: Recent advances in knowledge of the life of cephalopods
}

\author{
Ian G. Gleadall 1 - Natalie A. Moltschaniwskyj • Erica A. G. Vidal
}

Received: 3 December 2017/Revised: 14 December 2017/Accepted: 16 December 2017/Published online: 24 January 2018 (C) Springer International Publishing AG, part of Springer Nature 2018

\begin{abstract}
Nine papers comprising this special section of Hydrobiologia on cephalopod molluscs are introduced. These papers are a selection of those submitted following the CIAC 2015 conference held in Hakodate, Hokkaido, Japan, during 6-14 November, 2015.
\end{abstract}

Keywords Cephalopoda $\cdot$ Spermatangia ejaculate and male strategies for squid mating · Female octopus starvation and health during brooding $\cdot$ Sepia officinalis Hoyle's organ autophagy · Sepiolid paralarva morphology COI and identification · Body fluid osmolality osmoconforming - Effects of ocean

Guest editors: Erica A. G. Vidal, Ian G. Gleadall \& Natalie A. Moltschaniswskyj / Advances in Cephalopod Ecology and Life Cycles

I. G. Gleadall ( $₫)$

Tohoku University Graduate School of Agricultural Science, Aobayama Campus, Aoba 468-1, Aramaki, Sendai 980-0845, Japan

e-mail: octopus@bios.tohoku.ac.jp

N. A. Moltschaniwskyj

Fisheries Research, Department of Primary Industries, Taylors Beach Road, Taylors Beach, Nelson Bay, NSW 2315, Australia

e-mail: natalie.moltschaniwskyj@dpi.nsw.gov.au

E. A. G. Vidal

Center for Marine Studies, University of Parana, Cx.

P. 61, Pontal Do Paraná 83255-976, Brazil

e-mail: ericavidal2000@yahoo.com.br acidification on paralarval swimming behaviour . Species composition among coastal loliginid and oceanic onychoteuthid squid - Octopus mimus population

In recent years, the cephalopod molluscs have become much more widely known to the public at large, particularly since the 2010 FIFA World Cup football competition (when an octopus in a German aquarium successfully predicted the match winners; Dowling, 2010); and the Internet is now rife with interesting images and video clips of this intelligent and photogenic group of animals. There were an unusually large number of sightings of octopuses out of water in the UK in 2017 and it was a bumper year for octopus fishing in some parts of Japan. Both these phenomena may be related to global changes that seem to be involved in a steady rise in cephalopod abundance world-wide (Doubleday et al., 2016).

In view of the more prominent profile of cephalopods, and also their increasing importance in fisheries and aquaculture, there is a clear demand to learn more about their life. The CIAC 2015 conference, organized under the auspices of the Cephalopod International Advisory Council (CIAC), was held over 9 days in November of 2015 in Hakodate, a city in northern Japan famous for its annual landings of the Japanese flying squid, Todarodes pacificus (Steenstrup, 1880). The theme of the conference was Recent Advances in 
Cephalopod Science, and the main event was a 10 -session symposium held at the Hakodate Kokusai Hotel during 10-14 November. This symposium was preceded by five workshops held in parallel (8-9 Nov.) and a mini-workshop (6-7 Nov.), all held at the excellent facilities of the recently completed Hakodate Research Centre for Fisheries and Oceans. The fruits of this conference include the papers compiled for this special section of Hydrobiologia, along with those published in companion special issues of Marine Biodiversity (Vecchione et al., 2017), and the Journal of Natural History (Allcock et al., 2017).

This Hydrobiologia special section of nine papers spans the gamut of the life of cephalopods, from phenomena concerned with male strategies for squid mating and the maintenance of female octopus health during brooding, through features of paralarval life for coping with coastal salinity fluctuations and possible effects of ocean acidification on swimming behaviour, to investigations of species composition among coastal and oceanic squid and a population study of an important octopus resource.

To begin with, Apostólico \& Marian (2017) present a fascinating study of the phenomenon of intrasexual male dimorphism in the coastal squid Doryteuthis plei (Blainville, 1823), demonstrating that smaller sneaker males make up for their inferior size by investing in relatively more gonadal tissue and adaptations to release modest ejaculate volumes of large spermatozoa in spermatangia destined for the female buccal seminal receptacles. The larger sized consort males, in contrast, are shown to attach (near the oviductal apertures) much larger, hooked spermatangia, containing a large ejaculate of spermatozoa much smaller in both head and flagellum length than those of the sneakers.

Roumbedakis et al. (2017) have looked closely at what happens after female octopuses lay their eggs and enter the final phase of their life, when they stop eating to devote themselves to the vital tasks of guarding, cleaning and ensuring maximal oxygenation of their eggs until they hatch. Octopus maya Voss \& Solis, 1966, females are shown to be well adapted to live off the storage reserves in their body muscle and digestive gland, maintaining adequate health in terms of both physiological and immunological integrity for up to 40 days during this critical but programmed period of prolonged starvation.

Breaking out from the egg at hatching is not a simple task for a cephalopod, and in Sepia there is a sturdy casing to break out from successfully before a free-swimming life can begin. Cyran et al. (2017) have investigated the key choriolytic enzyme-producing Hoyle's organ (on the postero-dorsal surface of the hatchling mantle) to uncover more about its ecological and evolutionary significance. They found evidence that, in Sepia officinalis Linnaeus, 1758, the hatching enzymes are probably metalloproteases and, once the hatching function of this organ is over and it is no longer needed, its complete breakdown takes only a few days and involves a marked degree of autophagy, the first time this rare phenomenon has been determined for a deteriorating Hoyle's organ.

The paralarva is the initial planktonic form of many cephalopod species upon hatching and there then follows a species-specific and temperature-dependent period of several days to weeks or even months of feeding and growth in the plankton until the juvenile phase is reached and development proceeds towards the typical adult-like way of life. This paralarval phase is vulnerable to a higher level of mortality than at any other part of the life cycle, and since it is the major failing point of attempts to culture cephalopods much research is focussed onto understanding the reasons for, and ways to overcome, this high mortality. It is not surprising, then, that three of the papers in this special section are focussed on paralarvae.

A major problem with research on paralarvae encountered in the wild is how to identify them, when they may look very different from the adult form they are destined to develop into, and the paralarvae of closely related species may be very difficult to distinguish. To address such problems for sepiolid species off western Spain, Olmos-Pérez et al. (2017) combined the sequencing of the mitochondrial cytochrome c oxidase subunit I (COI) barcoding gene with simple morphometric measurements and morphological observations. Using statistical correlations, they were able to identify distinguishing morphological features with reasonable accuracy among the three consistently dominant sepiolid species.

Species with a planktonic paralarval phase have the potential for wider dispersal than holobenthic species, which hatch out as benthic juveniles (Villanueva et al., 2016). The dispersal of planktonic hatchlings is believed to occur in coastal areas, which are exposed to salinity fluctuations. Castellano et al. (2017) report the results of their field and laboratory studies to find out more about the salinity tolerance and dispersal 
potential of octopus paralarvae when exposed to water of different salinities. They found that by measuring whole body fluid osmolality it was possible to demonstrate the osmoconforming behaviour of paralarvae and their high capacity for fast osmotic equilibrium via tissue water regulation. This is facilitated by a large pool of free amino acids which apparently enables the paralarvae to regulate body fluid volume and to withstand environmental salinity variations during dispersal in coastal waters.

There are worries about possible effects of ocean acidification (due to increased $\mathrm{CO}_{2}$ levels) on statolith formation of paralarvae, so Zakroff et al. (2017) have looked for any possible effects on squid swimming performance, reporting on experiments to accurately track the swimming path and velocity of hatchling squids using a novel 3D tracking system. Although there were some hints of effects related to the seawater $p \mathrm{CO}_{2}$ levels in which the eggs were incubated, the effects on different cohorts were only loosely consistent, leading to the conclusion that ocean acidification may not have much effect at the $p \mathrm{CO}_{2}$ concentrations tested. This again seems to hint that cephalopods may be among the groups of animals that will prove to have a competitive edge under the currently changing global conditions (cf. Doubleday et al., 2016).

Oceanic squid have been the focus of fishing exploitation in recent decades (e.g., Chen, 2010) because they are often present in high abundance. Identifying them to species level is essential in order to track changes due to fishing effects on different populations, and to inform fisheries management decisions, but our knowledge of oceanic species in particular is still inadequate, even at the level merely of identifying them. Lischka et al. (2017) surveyed the commercially important onychoteuthid squids in the region of the Sargasso Sea, using both COI sequencing and morphology, and detected four species, doubling the number of known onychoteuthid species in the Atlantic.

The loliginids are a group of coastal squids that have long been exposed to intensive fishing pressure, but their identification, too, is a source of frustration despite several previous attempts at resolution using DNA sequencing. Jiang et al. (2017) report on a study using entire mitochondrial genomes to address some of the problems, here analysing nine Pacific species including eight present in the northwestern Pacific of which five were sampled directly from the East China
Sea. They discovered the likely presence of cryptic species among some of the species analysed and recommend that further careful sampling will be required in the future in order to improve the species resolution necessary for effective fisheries management of these coastal squids.

The final paper considers the distribution of Octopus mimus Gould, 1852, a southeastern Pacific relative of the Octopus vulgaris species complex. This is one of the most commercially valuable groups of octopus species yet very little is known about their population structure and biogeographic distribution, despite the fact that representatives of this group appear to be present throughout subtropical to temperate seas of all continents except Antarctica. PardoGandarillas et al. (2017) surveyed a large number of $O$. mimus from various collecting sites throughout its range and have been able to detect differences that provide useful information about the population, not only as it is at present but also as it was during the recent glacial maximum.

The 5-day symposium that stimulated the publication of these papers consisted of 104 consecutive oral presentations over 10 sessions: Behaviour (18 presentations); Biodiversity and Conservation (4); Reproduction (12); Genetics and Evolution (11); Physiology (12); Life History and Marine Ecosystems (9); Climate Change (7); Fisheries Management (13); Systematics and Biogeography (16); and Culture and Welfare (2). There were also 152 posters of exceptional standard covering a wide range of highly original experimental approaches. Accounts of the symposium and workshops can be found on line at the CIAC web site (https://cephalopod.wordpress.com).

The conference was sponsored by 23 local, national, academic and commercial organizations under the gentle persuasion and against the solid background of the reputation of the Conference Chair, Yasunori Sakurai, Professor Emeritus of Hokkaido University Faculty of Fisheries. The conference ran smoothly from start to finish thanks to the contribution of many individuals, coordinated by the highly competent efforts of John Bower and Dharmamony Vijai.

The next CIAC conference will be held during 10-16 Nov., 2018, in St Petersburg, Florida, with workshops on 10-11 Nov. and the symposium on 12-16 Nov. Discussions are also under way for preconference meetings on aquaculture and the 
Caribbean and Gulf of Mexico cephalopod fauna to take place in Sisal, Mexico.

\section{References}

* Since one of us is a co-author of these papers, they were edited independently by members of the Hydrobiologia Editorial Board.

Allcock, A. L., H. Judkins \& Y. Sakurai, 2017. Editorial. Recent advances in cephalopod science. CIAC 2015 special issue. Journal of Natural History 51(43-44): 2565-2567.

Apostólico, L. H. \& J. E. A. R. Marian, 2017. Dimorphic male squid show differential gonadal and ejaculate expenditure. Hydrobiologia. https://doi.org/10.1007/s10750-017-3145-z.

*Castellano, C. G., M. P. T. Veiga, F. S. Mazzini, E. A. G. Vidal \& C. A. Freire, 2017. Paralarvae of Octopus vulgaris type II are stenohaline conformers: relationship to field distribution and dispersal. Hydrobiologia. https://doi.org/10. 1007/s10750-017-3458-y.

Chen, C.-S., 2010. Abundance trends of two neon flying squid (Ommastrephes bartramii) stocks in the North Pacific. ICES Journal of Marine Science 67(7): 1336-1345. https:// doi.org/10.1093/icesjms/fsq063.

*Cyran, N., A. Palumbo, W. Klepal, E. A. G. Vidal, Y. Staedler, J. Schönenberger \& J. von Byern, 2017. The short life of the Hoyle lorgan of Sepia officinalis - formation, differentiation and degradation by programmed cell death. Hydrobiologia. https://doi.org/10.1007/s10750-017-3291-3.

Doubleday, Z. A., T. A. A. Prowse, A. Arkhipkin, G. J. Pierce, J. Semmens, M. Steer, S. C. Leporati, S. Lourenço, A. Quetglas, W. Sauer \& B. M. Gillanders, 2016. Global proliferation of cephalopods. Current Biology 26(10): R406-R407.
Dowling, T. 2010. Paul the octopus: the accidental hero. The guardian, 8 Dec. 2010. [Available on internet https://www. theguardian.com/commentisfree/2010/dec/08/paulpsychic-octopus-accidental-hero]. Accessed October 2017.

Jiang, L., L. Kang, C. Wu, M. Chen \& Z. Lv, 2017. A comprehensive description and evolutionary analysis of 9 Loliginidae mitochondrial genomes. Hydrobiologia. https://doi.org/10.1007/s10750-017-3377-y.

Lischka, A., H. E. Braid \& K. S. R. Bolstad, 2017. DNA barcoding from the hooked squids (Cephalopoda: Onychoteuthidae) of the Sargasso Sea. Hydrobiologia. https://doi. org/10.1007/s10750-017-3189-0.

Olmos-Pérez, L., Á. Roura, G. J. Pierce \& Á. González, 2017. Sepiolid paralarval diversity in a regional upwelling area of the NE Atlantic. Hydrobiologia. https://doi.org/10.1007/ s10750-017-3186-3.

Pardo-Gandarillas, M. C., C. M. Ibáñez, C. Yamashiro, M. Mémdez \& E. Poulin, 2017. Demographic inference and genetic diversity of Octopus mimus (Cephalopoda: Octopodidae) throughout the Humboldt Current System. Hydrobiologia. https://doi.org/10.1007/s10750-017-3339-4.

Roumbedakis, K., M. Mascaró, M. L. Martins, P. Gallardo, C. Rosas \& C. Pascual, 2017. Health status of post-spawning Octopus maya (Cephalopoda: Octopodidae) females from Yucatan Peninsula, Mexico. Hydrobiologia. https://doi. org/10.1007/s10750-017-3340-y.

Vecchione, M., E. M. Jorgensen \& Y. Sakurai, 2017. Editorial: recent advances in the knowledge of cephalopod biodiversity. Marine Biodiversity 47: 619-620.

Villanueva, R., E. A. G. Vidal, F. Á. Fernández-Álvarez \& J. Nabhitabhata, 2016. Early mode of life and hatchling size in cephalopod molluscs: influence on the species distributional ranges. PLoS ONE 11(11): e0165334.

Zakroff, C., A. Mooney \& C. Wirth, 2017. Ocean acidification responses in paralarval squid swimming behavior using a novel 3D tracking system. Hydrobiologia. https://doi.org/ 10.1007/s10750-017-3342-9. 